Revista Revoluciones, vol. 1, núm. 1, 2019, pp. 1-3.

\title{
El despertar de una nueva era: colonización y el camino hacia la revolución.
}

\section{Huanca-Arohuanca, Jesús Wiliam.}

Cita:

Huanca-Arohuanca, Jesús Wiliam (2019). El despertar de una nueva era: colonización y el camino hacia la revolución. Revista Revoluciones, 1

(1), 1-3.

Dirección estable: https://www.aacademica.org/jesus.wiliam.huancaarohuanca/7 ARK: https://n2t.net/ark:/13683/pu1Y/9v1

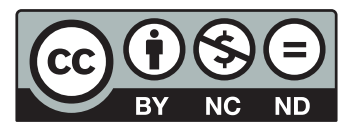




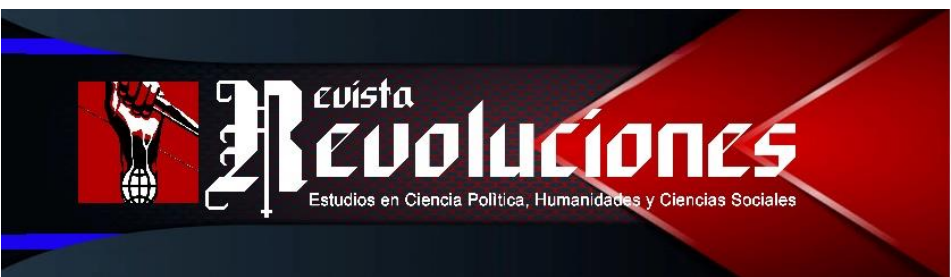

\title{
EDITORIAL
}

\section{EL DESPERTAR DE UNA NUEVA ERA: COLONIZACIÓN Y EL CAMINO HACIA LA REVOLUCIÓN}

\section{The awakening of a new era: colonization and the road to revolution}

\author{
Jesús Wiliam Huanca-Arohuanca ${ }^{1}$ \\ UNIVERSIDAD NACIONAL DE SAN AGUSTÍN DE AREQUIPA \\ PERÚ \\ jhuancaar@unsa.edu.pe \\ https://orcid.org/0000-0002-7353-1166 \\ Editor-Jefe
}

La revolución, irónicamente y contra lo que la tradición liberal opina de ella, es un paso del desorden a una situación de mayor orden, de un caos absoluto a uno menor, teniendo siempre como objetivo la consecución de un orden total, algo así como una armonía social completa.

Ramos, Á. (2019). Larga vida a la tragedia: ensayo sobre la tragedia y la revolución. Daímon. Revista Internacional de Filosofía, (77), 121-134. https://doi.org/10.6018/daimon/296891

Hace ya algunos años, leyendo a Aristóteles, Descartes, Locke, Bacon, Kant, Hegel, Montesquieu, Holbach, Comte, Marx, Engels, Foucault, Lacan, Gadamer, Weber, Durkheim, Bourdieu, Parsons, Politzer y a todos los teóricos de la Escuela de Frankfurt, soñábamos con la consolidación de la revolución violenta con ciertos patrones de dominación

\footnotetext{
${ }^{1}$ Filósofo político e investigador social en el departamento de Filosofía con mención en Ética y Filosofía Política por la Universidad Nacional de San Agustín de Arequipa [UNSA], Perú. Maestrante en la facultad de Ciencias Jurídicas en Derecho Procesal y Administración de Justicia por la Universidad Católica de Santa María [UCSM], Perú. Docente de la Especialidad de Ciencias Sociales y Sociólogo por la Universidad Nacional del Altiplano [UNA-P], Perú. En la actualidad dirige la Revista Revoluciones: Estudios en Ciencia Política, Humanidades y Ciencias Sociales. Así mismo, es revisor de la Revista Educación y Sociedad de la Universidad de Ciego de Ávila Máximo Gómez Báez, Cuba y la Revista Innova Educación del Instituto Universitario de Investigación [INUDI], Perú. Áreas que maneja: Filosofía, Ciencia Política, Ciencias Sociales, Investigación, Políticas Educativas para el Desarrollo Sostenible y Sustentable, Historia Latinoamericana, Sociología y Gestión Pública. Impacto académico: tiene publicaciones a nivel internacional en SCOPUS, Web of Science y Scielo que recae en países como; Colombia, España, Ecuador, Venezuela y Cuba; a nivel local tiene publicaciones en todas las regiones de la República Democrática del Perú.
} 
hegemónica. Al notar que la lucha de clases, aunque con distintos rasgos, podía seguir redefiniéndose una y otra vez en los atrios de las lecturas plasmados en horas de debates que nos llamaba a la revolución urgente, hacía sospechar que tal estado de cosas, representaría serios cambios en la estructura de los sistemas de dominación. Así mismo, aquella Universidad situada en el Altiplano Aymara-Quechua del Perú con una serie de precariedades, limitaciones, inquietudes y desfalcos, nos hacía creer ingenuamente a través de los que enseñan en la misma, que la revolución con odio era posible. Aunque no conocíamos a buenos referentes del entorno, excepto al Amauta José Carlos Mariátegui, al indigenista Gamaniel Churata como al pedagogo José Antonio Encinas y al Anarquista Manuel Gonzales Prada que ya se habían sacudido del yugo alienatorio, nosotros aun insistíamos en la revolución socialista que nada tenía que ver con los fundamentos mismos de la democracia porque el espacio histórico ya era distinto para nuestra época.

Con los años de pericia en el tema, nos dimos cuenta que el camino de la revolución era otro, y lo que nos habían enseñado los que seguían el manual del comunismo ya en colapso, no era cierto en su esencia. Conociendo un poco más a Mariátegui y Politzer nos acercamos a entender el cambio social en la facticidad misma de los que habitan la periferia y a los que se sirven de ella. Cuando estábamos a puertas de entrar al siglo actual, insertamos a nuestro lenguaje a teóricos como Vattimo, Lyotard, Habermas, Marcuse, Bauman y Freud quienes nos ayudarían a entender mejor la subjetividad de los sujetos ontológicos bordeados por los medios fácticos y la digitalización que parecía escapar de aquella liquidez al cual nos sometíamos. Así mismo, estudiamos muy de cerca a Heidegger, Sartre, Lukács, Arendt, Althusser, Badiou, Cortina, Bunge, Mouffe y Žižek en la resonancia de no perder de vista el camino hacia la revolución, que seguía muy ligada a la episteme proveniente del occidente anglosajón racista/sexista/patriarcal/dominante en todos los espacios.

Pero todo cambiaría cuando empezamos a analizar y conocer al Grupo Decolonial representado por insignes personajes como; Aníbal Quijano, Immanuel Wallerstein, Ramón Grosfoguel, Sylvia Wynters, Edgardo Lander, Walter Mignolo, Arturo Escobar, Enrique Dussel, Chandra Mohanty, Zine Magubane, Fernando Coronil, Santiago Castro-Gómez, Oscar Guardiola, Javier Sanjinés, Catherine Walsh, Michael Ennis, Freya Schiwy, José Saldívar, Nelson Maldonado-Torres, Lewis Gordon, Boaventura de Sousa, Carolina Santamaría, Juan Cajigas-Rotundo, Fernando Garcés, Mónica Espinosa y Juliana Flórez-Flórez. Todos ellos comprendían que la revolución antes que cualquier otra motivación debía materializarse en denunciar los intentos de cualquier discurso que diga que vivimos ahora en un mundo descolonizado y poscolonial. Porque hoy, "asistimos, más bien, a una transición del colonialismo moderno a la colonialidad global, proceso que ciertamente ha transformado las formas de dominación desplegadas por la modernidad, pero no la estructura de las relaciones centro-periferia a escala mundial" ${ }^{2}$. En consecución, salta a la vista como las instituciones patriarcales siguen poniendo de rodillas a nuestros pueblos subalternos, aumentando el dolor y a la invitación a una revolución justificada.

\footnotetext{
${ }^{2}$ Castro-Gómez, S., \& Grosfoguel, R. (2007). El giro decolonial. Reflexiones para una diversidad epistémica más allá del capitalismo global. Bogotá: Siglo del Hombre Editores.
} 
Desde los espacios locales era imposible comprender y analizar las dinámicas/fenoménicas sociopolíticoeconómicos que ha vivenciado el país de "todas las sangres" como diría otro de los grandes indigenistas como, José María Arguedas. No solo el Perú estaba en una situación crítica, sino también la América Latina de colores del cual todos somos parte. Por ello y por todo, sabíamos que solo un pensamiento crítico-consciente con la base teórica suficiente, podía lograr ese gran cambio en las estructuras y superestructuras para un orden total y una paz completa soñado por todos/as los originarios/ias.

En contextos cataclísmicos donde el poder de la crítica a través de los vocablos es lo único capaz de poner en jaque a las hegemonías colonizadoras, se hace cada vez más indispensable servirse de él como fuente de cambio de la realidad líquida, porque solo con los intentos de revolución epistémica en medio de la invisibilización, la postergación y la injusticia social para todos los pueblos de América Latina, será posible el sueño que millones de indígenas tenemos.

Con la Revista Revoluciones. Estudios en Ciencia Política, Humanidades y Ciencias Sociales asumimos hoy el compromiso de los que han muerto intentando la revolución en todos los pueblos emergentes/periféricos/subalternos. Ahí está la esencia de conformar este análisis que convocará a espacios de diálogo sumergidos en ideas, utopías y práxis, sin ningún tipo de prejuicios ni limitaciones de carácter social-dogmático. La revista tiene una coyuntura transformadora-problemática-sofocadora que plantea una contrahegemonía ante los poderes sistémicos del capitalismo sin piedad. 